\title{
FOLATE AND SYNTHETIC FOLIC ACID INTAKE, SERUM B VITAMIN AND HOMOCYSTEINE CONCENTRATIONS, AND COGNITIVE IMPAIRMENT IN ELDERLY BRAZILIANS
}

\author{
V. Ferri Ross Perucha ${ }^{1}$, R. de Cássia de Aquino ${ }^{1}$, N. Gaspareto ${ }^{1}$, E.M. Guerra-Shinohara², \\ P. Mendonça da Silva Amorim², V. d'Almeida
}

\begin{abstract}
Background: An increased risk of cognitive decline in the elderly with B12 deficiency has been associated with excessive synthetic folic acid in food fortification and supplements. Objectives: To assess the dietary folate and folic acid intake from food fortification, as well as serum vitamin B12, folate, iron, and homocysteine concentrations among the elderly and their relationships with cognitive changes. Design: Cross-sectional, observational study. Setting and Participants: Community-dwelling elderly (N = 40), predominantly female $(90 \%)$, with an average age of 69 years. Measurements: Dietary intake information was collected using four 24-hour dietary recalls, adjusted for iron and folic acid in fortified flour and supplements. Serum vitamin B12, B6, folate, iron, and homocysteine concentrations were determined. Cognitive function was assessed using the Mini-Mental State Examination, adjusted for educational level. Results: Possible serum vitamin B12 deficiency ( $<258$ pmol/L) was present in $5 \%$ of the elderly participants, while $27.5 \%$ had possible functional deficiency $(<400 \mathrm{pmol} / \mathrm{L})$. No serum folate deficiency $(<6.8 \mathrm{nmol} / \mathrm{L})$ was observed; however, $15 \%$ had possible deficiency $(<13.6 \mathrm{nmol} / \mathrm{L})$, and $7.5 \%$ had supraphysiological levels. Hyperhomocysteinemia $(\geq 15 \mu \mathrm{mol} / \mathrm{L})$ was present in $65 \%$ of the sample. Almost half of the participants (47.5\%) showed cognitive impairment. There were no significant relationships between the Mini-Mental State Examination results and the B12, folate, iron, and homocysteine concentrations. However, the participants with serum vitamin B12 levels $<400 \mathrm{pmol} / \mathrm{L}$ tended to have poorer Mini-Mental State Examination scores, which were related to older age $(P=0.045)$ and changes in the oral cavity $(P=0.034)$. In addition, folic acid consumption was inversely related with serum vitamin B12 levels $(\mathrm{P}=0.030)$. Macrocytosis was not observed. Conclusions: Although Mini-Mental State Examination-assessed cognitive impairment was not related with the investigated biochemical variables, increased folic acid consumption seems to have a negative impact on vitamin B12 metabolism; therefore, fortification may be contributing to functional disability and masking hematological signs in the elderly.
\end{abstract}

Key words: Cobalamin, folate, synthetic folic acid, homocysteine, cognition.

\section{Introduction}

The longevity of the Brazilian population has steadily increased in recent decades, following the global trend, and projections for 2050 place Brazil among the countries with the largest elderly populations in the world (1). However, longevity is not always associated with healthy aging. Micronutrient deficiencies, which are exacerbated by the presence of disease, and the use of multiple medications, are common among the elderly (2).

Aging-related vitamin B12 (cobalamin) deficiency is

1. Postgraduate Program in Science Aging, São Judas Tadeu University- USJT, São Paulo-SP, Brazil; 2. Department of Clinical Analyses and Toxicology, School of Pharmaceutical Science, University of São Paulo- FCF-USP - São Paulo-SP, Brazil; 3. Laboratory for Inborn Errors of Metabolism, Federal University of São PauloUNIFESP - São Paulo-SP, Brazil

Corresponding Author: Viviane Ferri Ross Perucha, Universidade São Judas Tadeu, R. Taquari, 546 - Mooca, São Paulo/SP, CEP 03166-000, Brazil, +55 11 2799-1677, viviperucha@gmail.com.

Received August 25, 2016

Accepted for publication November 8, 2016 particularly common, in both developed and developing countries. Vitamin B12 malabsorption is a principal cause, affecting $30-40 \%$ of the elderly (3). The etiologic factors include atrophy of the gastric mucosa and reduced secretion of hydrochloric acid and intrinsic factor, which are affected by atrophic gastritis, pernicious anemia, and Helicobacter pylori infection as well as antacids and diabetes medications, such as omeprazole and biguanides, respectively (4).

The clinical manifestations of vitamin B12 deficiency range from asymptomatic to very severe cases. It is generally characterized by megaloblastic anemia associated with neuropsychiatric symptoms, which may be irreversible $(3,4)$. In addition to neuropathy, memory deficits, cognitive impairment, depressive disorders, dementia, Alzheimer's disease, and Parkinson's disease are also reported (5).

The methylation metabolic pathway interrelates the metabolism of vitamin B12, folate, and homocysteine 
(Hcy) $(3,6)$; based on disruption of this pathway, epidemiological studies have associated an increased risk of cognitive decline in vitamin B12-deficient elderly people with consumption of high doses of synthetic folic acid (FA), used in flour fortification and supplements (7, 8 ). The increasing cognitive decline and demyelination could be explained by the "methyl trap" hypothesis. This hypothesis states that vitamin B12 deficiency results in a state of hypomethylation caused by the bound 5-methyltetrahydrofolate, which cannot be recycled into tetrahydrofolate, whose reaction would be mediated by the enzyme methionine synthase (responsible for the conversion of Hcy to methionine) that is dependent on vitamin B12 as a cofactor. In addition, the retained 5-methyltetrahydrofolate cannot be used in DNA synthesis, resulting in symptoms identical to that of the anemia (megaloblastic) that occurs in cases of folate deficiency. This condition can be aggravated by high doses of FA, which tend to correct the anemia but not the neurological symptoms $(3,6)$. It is also suggested that the oxidative effects of non-metabolized FA prevent the action of vitamin B12 in cytosolic and mitochondrial compartments; this explains the increase in both Hcy and methylmalonic acid (MMA) and characterizes the worsening of functional vitamin B12 deficiency $(7,9)$. In animal models, negative metabolic effects associated with excess FA seem to be influenced by genetic polymorphisms of enzymes related to methylation such as MTHFR 677C>T (10), which is also associated with hyperhomocysteinemia and neurological disorders in humans (11).

Another concern with FA fortification is the presence of cognitive impairment in elderly patients with normal, or close to normal, serum vitamin B12 values, accompanied by an increase in the level of functional biomarkers (12). The effect of FA in reducing macrocytosis, which may mask the hematological signs of vitamin B12 deficiency, has also been reported $(8,12,13)$.

Studies also indicate that excess folate might facilitate the progression of pre-neoplastic lesions, increasing the risk of cancer in humans (14). Collectively, these results have stimulated discussions of the undesirable effects of mandatory FA fortification in the general population and elderly, which are in contrast to the potential benefits of fortification for women of childbearing age, specifically related with risk reduction for neural tube defects in the fetus $(6,14)$.

Given that vitamin B12 deficiency is a common problem with aging (3) and due to the policy of fortifying flour with FA and iron in Brazil (15), this study aimed to assess dietary folate and FA intake and serum concentrations of vitamin B12, vitamin B6, folate, iron, and Hcy as well as their relationships with cognitive impairment in community-dwelling elderly.

\section{Methods}

\section{Study Population}

We included elderly participants (aged $\geq 60$ years) of extension projects for seniors at the São Judas Tadeu University (USJT), a private Brazilian institution, located in São Paulo-SP. All participants were informed of the objectives and procedures of the research and the risks and benefits described in the Terms of Consent Form. The project was approved by the Research Ethics Committee (REC) of USJT, protocol 096/2011. Data collection was conducted between February and July 2012.

\section{Nutritional and Anthropometric Assessments}

The initial interview collected personal details, sociodemographic information, current and previous clinical history, medications in use, general health conditions, body weight history, physical activity, general data on food, and a 24-hour dietary recall (R24h). In addition, an anthropometric assessment was conducted by qualified nutritionists using recommended techniques and consisted of body weight, standing height, body mass index (BMI), and waist circumference (WC).

Nutritional status was classified using BMI and was calculated using the proposal of the Pan American Health Organization (16). The World Health Organization (WHO) waist circumference cutoff points for adults were used (17), because there are no reference values for the elderly.

Information about changes in the oral cavity and tongue was collected, because these are related with vitamin B nutritional status, especially that of vitamin B12 and folate (18).

\section{Assessment of Food Intake}

Four R24h were performed, the first during the initial interview and the other three on other days of the week at average intervals of 10 days and including a weekend day (Sunday). Food consumption was collected with the four R24h using usual measures (e.g., measuring cup, bowl) and converted to grams/mL with the aid of usual measure tables or guides; then, food intake was calculated according to energy and the macro- and micronutrient composition. The composition and dosage of supplements used by the participants were determined using the labels or prescriptions, and the amounts for those containing vitamin B12, vitamin B6, or FA were added to the intake values. To adjust for bioavailability, the FA supplement values, in $\mu \mathrm{g}$, were converted to dietary folate equivalents (DFEs), in $\mu \mathrm{g}$, by multiplying by a conversion factor of 1.7 (19).

To evaluate food intake, a database with 376 foods was created, based on the 2011 Brazilian Table of Food 
Composition (TACO), 4th edition (20), and the USDA on-line version (Release 24) (21) was used to adjust the levels of vitamin B12 and folate, because a national composition table that includes these two nutrients in national foods is not available. Also, it was necessary to adjust the folate and iron values in 48 foods produced with fortified flour, in accordance with the mandatory fortification policy for flour in Brazil (RDC 344); the following amounts were added for wheat flour, corn flour, corn meal, and corn flakes: $4.2 \mathrm{mg}$ iron/100 $\mathrm{g}$ food and $150 \mu \mathrm{g}$ folic acid/100 g food (15). Total folate was calculated as the sum of natural folate (dietary) and the synthetic form (FA present in foods and / or supplements). The principal nutrients of interest in the research, such as vitamin B12, vitamin B6, folate, FA, and iron, were adjusted for energy intake (per $1000 \mathrm{kcal}$ ).

\section{Biochemical Evaluation}

Blood collection and preparation of the biological material were performed in the laboratory of the Center for Pharmaceutical Studies at the USJT. The technical and operational recommendations for collection, storage, and transport were followed. Blood collection was performed in the morning after a minimum fasting period of 10 hours.

The serum concentrations of folate and vitamin B12 were determined using the microbiological method, with strains of Lactobacillus casei and Lactobacillus leichmannii, respectively. Plasma Hcy levels were determined using high performance liquid chromatography (HPLC) with fluorimetric detection and isocratic elution. Plasma vitamin B6 levels were determined using HPLC with ultraviolet detection and isocratic elution. A complete hemogram was performed on whole blood with EDTA anticoagulant using manual analysis of hematologic indices and employing blood extension and the Panoptic staining method (New Prov ${ }^{\circledR}$, Pinhais/PR, Brazil). Glucose was measured in plasma with fluoride anticoagulant, and the other biochemical tests (lipid profile, kidney function, and liver function) were conducted using serum samples. For general biochemical analysis, the Bio-2000 model (Bio-Plus ${ }^{\circledR}$, Barueri/SP, Brazil) and specialized kits from Doles ${ }^{\circledR}$ (Goiania/GO, Brazil) were used. The Iron kit for the modified Goodwin method was used for serum iron.

To analyze the biochemical variables, cutoff points described in the literature were adopted: vitamin B12, possible deficiency $(<258 \mathrm{pmol} / \mathrm{L})$ (22) or possible functional deficiency $(<400 \mathrm{pmol} / \mathrm{L})(23)$; serum folate, deficiency $(<6.8 \mathrm{nmol} / \mathrm{L}$ or $<3 \mathrm{ng} / \mathrm{mL})$, possible deficiency $(<13.6 \mathrm{nmol} / \mathrm{L}$ or $<6 \mathrm{ng} / \mathrm{mL})$, or supraphysiological ( $>45.33 \mathrm{nmol} / \mathrm{L}$ or $>20 \mathrm{ng} / \mathrm{mL}$ ) (24); vitamin B6, deficiency ( $<20 \mathrm{nmol} / \mathrm{L}$ pyridoxal phosphate) (19); and hyperhomocysteinemia (Hcy $\geq 15 \mu \mathrm{mol} / \mathrm{L}$ ). There is no consensus in the literature regarding the cutoff points of Hcy for the elderly (usually $\geq 12-15 \mu \mathrm{mol} / \mathrm{L}$ ).
The higher limit adopted also considered the acceptable Hcy level for elderly exposed to FA fortification and/or supplementation (25).

For the remaining biochemical markers (serum iron, blood count, lipid profile, and kidney and liver function), cutoff points suggested by the laboratory were adopted. Anemia and macrocytosis were determined using hemoglobin levels (women: $<11.7 \mathrm{~g} / \mathrm{dL}$; men: $<13.5 \mathrm{~g} /$ $\mathrm{dL}$ ) and mean corpuscular volume (women: $>100 \mathrm{fL}$; men: $>95 \mathrm{fL}$ ), respectively. Serum creatinine levels were used to assess kidney function.

\section{Evaluation of Cognitive Function}

The Mini-Mental State Examination (MMSE) was used to evaluate cognitive function. Because education and age are very influential on MMSE scores, the Brazilian version was used, with possible scores of $0-30$ points (26).

\section{Statistical Analysis}

A statistical significance of $5 \%$ was adopted, and SPSS version 17.0 (SPSS Inc., Chicago, IL) was used for all analyses. Quantitative data are described as the arithmetic mean and standard deviation (SD), median and interquartile range (equivalent to the 25th and 75th percentiles of the median values), and/or categorized as the cut-offs or adopted reference standards. Qualitative data are categorized and described according to the frequency distribution percentage.

Normality was verified using the Skewness-Kurtosis test. Pearson correlation tests were performed for quantitative variables with a normal distribution, and Spearman correlation tests were used for the variables with an asymmetric distribution. The Student's $t$ test was used to analyze differences between variables with normal distributions, and the Mann-Whitney test was used to analyze differences between variables with an asymmetrical distribution.

\section{Results}

\section{General Characteristics of the Elderly Participants}

The sample included 40 elderly people (90\% women), with a mean age of 68.97 years $(S D \pm 6.51)$. All were physically independent and participated in extension projects for seniors at a university. Educational level was diverse, with $65 \%$ of participants completing up to 8 years of education. The most common clinical conditions were hypertension, diabetes, dyslipidemia, and metabolic syndrome. Almost half of the participants were overweight or obese $(47.5 \%)$, and the majority $(75.0 \%)$ had a considerably increased metabolic risk (Table 1).

Clinical signs involving the gastrointestinal tract, 
such as changes in the oral cavity or tongue, were cited by almost half of the population (45\%) (Table 1), and $15 \%$ reported changes of the tongue (burning, cracking, pain, redness, paleness, or smooth texture). The use of vitamin B12 or FA supplements was reported by $5 \%$ of the participants, and the use of vitamin B6 supplements was reported by $7.5 \%$ of the participants.

Table 1

Primary general characteristics of the elderly sample (São Paulo, 2013)

\begin{tabular}{lcc}
\hline VARIABLE & $\mathbf{n}$ & $\%$ \\
\hline GENERAL CHARACTERISTICS & & \\
$\quad$ Age 60-70 years & 27 & 67.5 \\
$\quad$ Female sex & 36 & 90.0 \\
$\quad$ Lives alone & 12 & 30.0 \\
$\quad$ Up to 8 years education & 26 & 65.0 \\
$\quad$ Retired/ pensioner & 35 & 87.5 \\
GERIATRIC CHANGES & & \\
$\quad$ Changes in the oral cavity/tongue & 24 & 60.0 \\
LIFESTYLE HABITS & & \\
$\quad$ Current and former smokers & 15 & 37.5 \\
$\quad$ Physical activity & 29 & 72.5 \\
$\quad$ Alcohol intake (current or previous) & 8 & 20.0 \\
MORBIDITIES & & \\
Systemic arterial hypertension & 27 & 67.5 \\
Diabetes mellitus & 6 & 15.0 \\
Dyslipidemia & 32 & 80.0 \\
Metabolic syndrome (ATP III) & 27 & 67.5 \\
Gastritis or ulcer & 11 & 27.5 \\
Reported depression & 4 & 10.0 \\
Memory complaints & 10 & 25.0 \\
MEDICATION & & \\
Polypharmacy ( $\geq 5$ drugs) & 20 & 50.0 \\
Antiulcer & 17 & 42.5 \\
Metformin & 7 & 17.5 \\
ANTHROPOMETRIC EVALUATION & & \\
Low body mass index (BMI) & 5 & 12.5 \\
Overweight/obese (BMI) & 19 & 47.5 \\
$\quad$ Greatly increased metabolic risk (waist & 30 & 75.0 \\
circumference) & & \\
COGNITIVE EVALUATION & & \\
Poor Mini-Mental State Examination score & 19 & 47.5 \\
\hline
\end{tabular}

\section{Relationships with MMSE}

The average MMSE score was $26.2(\mathrm{SD} \pm 1.7)$ points, and almost half of the participants $(47.5 \%)$ had cognitive impairment, after adjusting for education (Table 1). There were no significant differences in serum vitamin B12, folate, iron, or Hcy levels between the MMSE classifications $(P \geq 0.05)$. However, participants with low cognitive performance had lower serum vitamin B12 levels (457 vs $487 \mathrm{pmol} / \mathrm{L}$ ) and lower serum folate levels ( 24.7 vs $26.8 \mathrm{nmol} / \mathrm{L}$ ) than those with normal cognitive performance (Table 2). There were also no differences in plasma vitamin B6 levels between MMSE classifications ( $P=0.797$; data not shown).

There were also no significant differences in the MMSE score between the classifications of serum vitamin B12, folate, or Hcy concentration. However, the mean MMSE score was almost one point less ( 25.45 vs 26.59 points) among those with possible functional vitamin B12 deficiency $(<400 \mathrm{pmol} / \mathrm{L})$ than in those with a better B12 status ( $\geq 400 \mathrm{pmol} / \mathrm{L})$, indicating a trend. In addition, participants with possible functional deficiency were older than those with better vitamin B12 status (72 vs 67 years; $\mathrm{P}=0.045$; Table 3$)$. Complaints of oral cavity changes were more frequent $(72.7 \%$ vs $34.5 \%)$ among those with serum B12 levels $<400 \mathrm{pmol} / \mathrm{L}$ than those with better vitamin $\mathrm{B} 12$ status $(\mathrm{P}=0.034$; data not shown $)$.

Regarding folate, participants with possible deficiency $(<13.6 \mathrm{nmol} / \mathrm{L})$ also had an MMSE score around one point higher (27.17 vs 26.12 points) and were older (70.50 vs 67.00 years) than those with a higher folate level $(\geq 13.6 \mathrm{nmol} / \mathrm{L})$, although these differences were not significantly different (Table 3 ).

Plasma Hcy levels were not related with MMSE scores $(\mathrm{P} \geq 0.05$; Tables 2 and 3). Participants with plasma Hcy levels $\geq 15 \mu \mathrm{mol} / \mathrm{L}$ were significantly older than those with lower Hcy levels $(<15 \mu \mathrm{mol} / \mathrm{L} ; 69$ vs 67 years; $\mathrm{P} \geq$ 0.05; Table 3).

Age was positively correlated with Hcy levels ( $\mathrm{r}=$ $0.427, \mathrm{P}=0.006$ ) and negatively correlated with serum folate levels $(r=-0.336 ; P=0.034)$ (data not shown). 
Table 2

Median serum or plasma vitamin B12 (pmol/L), folate (nmol/L), homocysteine ( $\mu \mathrm{mol} / \mathrm{L})$, and iron $(\mu \mathrm{g} / \mathrm{dL})$ levels and their relationships with the Mini-Mental State Examination (MMSE) classification of elderly participants (São

Paulo, 2013).

\begin{tabular}{lccc}
\hline $\begin{array}{l}\text { CONCENTRATIONS } \\
\text { Median (IQR) }\end{array}$ & Low (N = 19) & MMSE \\
\hline SERUM VITAMIN B12 $^{1}$ & $456.553 \mathrm{pmol} / \mathrm{L}(309.90-605.20)$ & $486.605 \mathrm{pmol} / \mathrm{L}(406.46-559.90)$ & 0.526 \\
SERUM FOLATE $^{2}$ & $24.700 \mathrm{nmol} / \mathrm{L}(14.50-34.60)$ & $26.800 \mathrm{nmol} / \mathrm{L}(16.30-38.70)$ & 0.579 \\
PLASMA HOMOCYSTEINE $^{1}$ & $15.427 \mu \mathrm{mol} / \mathrm{L}(12.65-17.60)$ & $16.891 \mu \mathrm{mol} / \mathrm{L}(13.85-19.32)$ & 0.181 \\
SERUM IRON $^{2}$ & $123.79 \mu \mathrm{g} / \mathrm{dL}(99.00-142.00)$ & $109.48 \mu \mathrm{g} / \mathrm{dL}(89.00-138.50)$ & 0.111 \\
\hline
\end{tabular}

(1) Student $t$ tests were used to compare values for variables with a normal distribution (2) Mann-Whitney tests were used to compare values for variables without a normal distribution; IQR, interquartile range (25th percentile to 75 th percentile).

Figure 1

Median consumption of total folate ( $\mu \mathrm{g}$ Dietary Folate Equivalent [DFE]) or synthetic folic acid $(\mu \mathrm{g})$ from fortification, reported as raw data (A) and adjusted for energy (1000 kcal) (B), and their relationships with the Mini-Mental State Examination (MMSE) classification of the elderly participants (São Paulo, 2013)
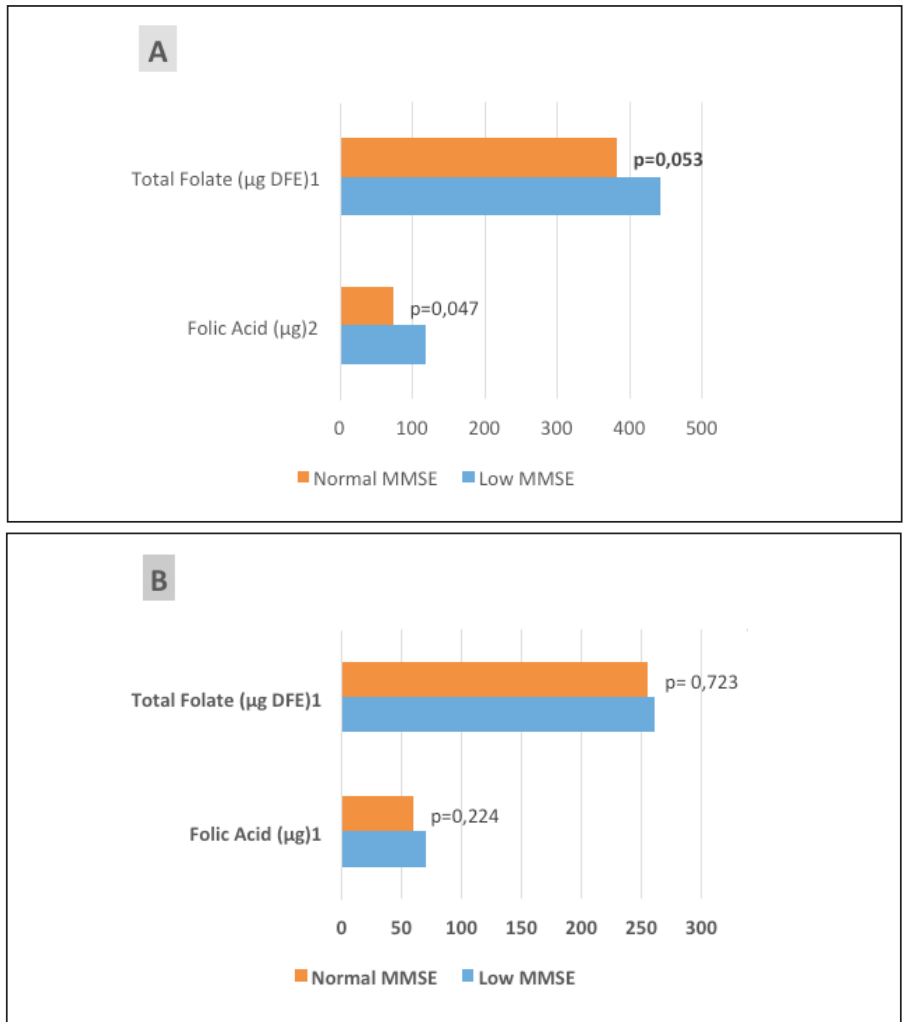

(1) Student $t$ tests were used to compare values for variables with a normal distribution (2) Mann-Whitney tests were used to compare values for variables without a normal distribution. Total folate was calculated as the sum of that consumed via the diet and fortification.

\section{Folic Acid Intake and Relationships between Folate and MMSE scores and Vitamin B12 Concentrations}

Considering $1000 \mathrm{kcal}$-adjusted values (Fig. 1-B), both the average total folate intake $(261.3 \pm 43.1$ vs $256.0 \pm 49.9$ $\mu \mathrm{g}$ DFE; $\mathrm{P}=0.723)$ and FA intake from fortification (70.6 \pm 23.4 vs $60.7 \pm 27.3 \mu \mathrm{g} ; \mathrm{P}=0.224)$ were higher, but not significantly different, among participants with lower MMSE scores; however, the respective non-adjusted raw data (Fig. 1-A) were significantly different for FA intake $(73.9 \pm 27.3$ vs $119.0 \pm 23.4 \mu \mathrm{g} ; \mathrm{P}=0.047)$, and a trend was observed for total folate intake $(382.5 \pm 108.2$ vs $442.7 \pm$ $78.0 \mu \mathrm{g}$ DFE; $\mathrm{P}=0.053$ ).

\section{Figure 2}

Pearson correlations between serum vitamin B12 levels (pmol/L) and synthetic folic acid ${ }^{1}(\mu \mathrm{g})(\mathrm{A})$ and total folate intake $^{2}(\mu \mathrm{g}$ dietary folate equivalent [DFE]) (B) of the elderly sample (São Paulo, 2013)
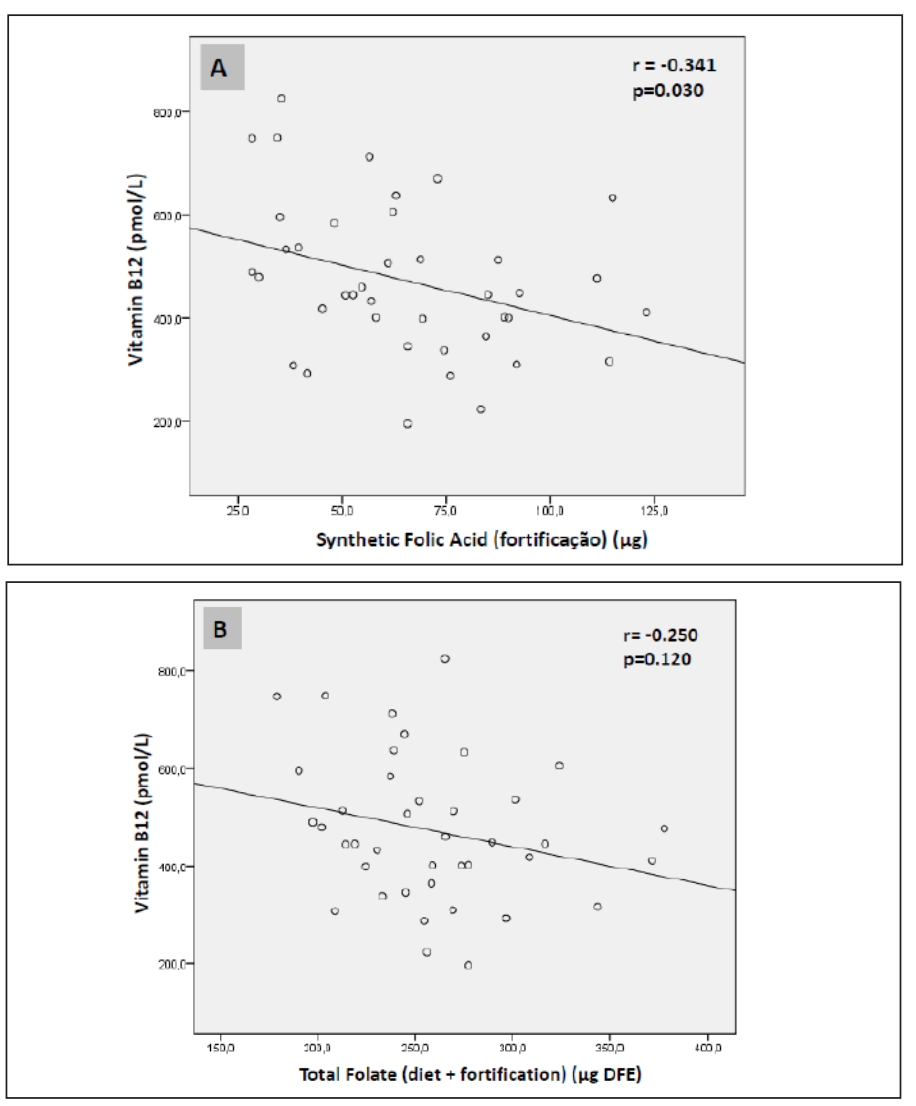

(1) Fortification, adjusted for energy intake (1000 kcal) (2) Diet + fortification, adjusted for energy intake (1000 kcal) 
Table 3

Relationships between serum or plasma vitamin B12 (pmol/L), folate (nmol/L), and homocysteine ( $\mu$ mol/L) levels and median Mini-Mental State Examination (MMSE) score and age of the elderly sample (São Paulo, 2013)

\begin{tabular}{|c|c|c|c|c|c|c|c|c|c|c|}
\hline \multirow[t]{2}{*}{ VARIABLE } & & \multicolumn{3}{|c|}{ SERUM VITAMIN B12 } & \multicolumn{3}{|c|}{ SERUM FOLATE } & \multicolumn{3}{|c|}{ PLASMA HOMOCYSTEINE } \\
\hline & & $<400 \mathrm{pmol} / \mathrm{L}$ & $\geq 400 \mathrm{pmol} / \mathrm{L}$ & $\mathrm{p}$ & $<13.6 \mathrm{nmol} / \mathrm{L}$ & $\geq 13.6 \mathrm{nmol} / \mathrm{L}$ & p & $\geq 15 \mu \mathrm{mol} / \mathrm{L}$ & $<15 \mu \mathrm{mol} / \mathrm{L}$ & $\mathrm{p}$ \\
\hline & $\mathrm{N}$ & 11 & 29 & & 6 & 34 & & 26 & 14 & \\
\hline MMSE Score & $\begin{array}{l}\text { Median }^{1} \\
\text { (IQR) }\end{array}$ & $\begin{array}{c}25.45 \\
(24.00-27.00)\end{array}$ & $\begin{array}{c}26.59 \\
(25.00-28.00)\end{array}$ & 0.075 & $\begin{array}{c}27.17 \\
(25.17-29.25)\end{array}$ & $\begin{array}{c}26.12 \\
(24.75-27.00)\end{array}$ & 0.191 & $\begin{array}{c}26.31 \\
(25.00-27.00)\end{array}$ & $\begin{array}{c}26.21 \\
(24.00-28.25)\end{array}$ & 0.878 \\
\hline AGE (years) & $\begin{array}{l}\text { Median }^{2} \\
\text { (IQR) }\end{array}$ & $\begin{array}{c}72.00 \\
(69.00-78.00)\end{array}$ & $\begin{array}{c}67.00 \\
(63.00-69.50)\end{array}$ & 0.045 & $\begin{array}{c}70.50 \\
(63.00-79.25)\end{array}$ & $\begin{array}{c}67.00 \\
(63.75-70.25)\end{array}$ & 0.382 & $\begin{array}{c}69.00 \\
(64.50-75.75)\end{array}$ & $\begin{array}{c}67.00 \\
(63.00-69.50)\end{array}$ & 0.378 \\
\hline
\end{tabular}

(1) Student $t$ tests were used to compare values for variables with a normal distribution (2) Mann-Whitney tests were used to compare values for variables without a normal distribution; IQR, interquartile range ( 25 th percentile to 75 th percentile).

FA intake from fortification was inversely correlated with serum vitamin B12 levels $(r=-0.341 ; P=0.030$; Fig. 2-A). The relationship between total folate intake and serum vitamin B12 levels was not statistically significant $(r=-0.250 ; P=0.120$; Fig. 2-B). Similarly, FA intake from fortification and supplements was inversely correlated with serum vitamin B12 levels $(r=-0.344 ; \mathrm{P}=0.030)$, while total folate intake was not significantly associated with vitamin $\mathrm{B} 12$ levels $(\mathrm{r}=-0.218 ; \mathrm{P}=0.176$; data not shown).

\section{Discussion}

Micronutrient status can affect cognitive function at any age. In the elderly, low serum B vitamin levels and high Hcy concentrations can influence memory and are considered risk factors for mild cognitive impairment, vascular dementia, and Alzheimer's disease $(5,27)$. Of the B vitamins that may affect Hcy level and neurological function $(11,27)$ and were measured in the present study, the rate of inadequacy was lowest for vitamin B6 (2.5\%); this is not surprising given that the subjects were active non-institutionalized elderly. In addition, vitamin B6 levels and MMSE classification were not related.

Consistent with the literature, where it is estimated that vitamin B12 deficiency affects $5-25 \%$ of the elderly (3), $5 \%$ of the sample in the present study had low serum vitamin B12 levels $(<258 \mathrm{pmol} / \mathrm{L})$, and the levels for $27.5 \%$ of the sample were in the at-risk range for functional deficiency $(<400 \mathrm{pmol} / \mathrm{L})$. The higher cutoff point for vitamin B12 was adopted as an alternative in the absence of specific functional biomarkers, such as MMA and holotranscobalamin (holo-TC), based on observations that levels $<400 \mathrm{pmol} / \mathrm{L}$ are associated with elevated MMA and Hcy levels (23), and consequently, with the risk of cognitive decline in elderly people (12).

The present study found evidence of a beneficial effect on cognitive function with the maintenance of higher serum vitamin B12 levels. There was an observed trend in MMSE scores, with a difference of approximately one point in the MMSE based on a serum vitamin B12 level cut-off $\geq 400 \mathrm{pmol} / \mathrm{L}(\mathrm{P}=0.075)$. Among the elderly in the Framingham Heart Study, lower B12 concentrations $(<257 \mathrm{pmol} / \mathrm{L})$ were related with a faster rate of decline in the MMSE score (0.35 points/year) over 8 years of follow-up, although no association was observed at baseline in the first cross-sectional analysis (28). Another result observed in the present study was that elderly subjects with functional vitamin B12 deficiency $(<400$ $\mathrm{pmol} / \mathrm{L}$ ) were older and more frequently reported alterations in the oral cavity, which can be related with anemia due to vitamin B12 or folate deficiency (18).

In the present study, although no statistically significant differences were observed between serum folate levels and MMSE classification, recent evidence suggests that high levels of folate, from FA consumption, increase the risk of cognitive decline in elderly people with low serum vitamin B12 levels $(7,8,29)$. The synthetic form of the vitamin has an approximate $80 \%$ bioavailability (19) and is slowly metabolized in humans (6), which may explain the results of the present study, including an absence of classic deficiency, and supraphysiological levels in $7.5 \%$ of the sample. The mean serum folate level was $29.12( \pm 21.62) \mathrm{nmol} / \mathrm{L}$; the average total folate intake $(628 \pm 1266 \mu \mathrm{g} /$ day $)$ was higher than the Recommended Dietary Allowance $(\geq 400$ $\mu \mathrm{g} /$ day) (19). According to a recent review (30), the mean serum folate level among elderly Brazilians in the postfortification period ranged from $24.7( \pm 6.9)$ to 28.6 ( \pm 11.3) $\mathrm{nmol} / \mathrm{L}$; consumption was not investigated.

Further analysis of food consumption in the present study provided another important result that agrees with growing evidence on the risks of fortification-isolated FA from fortification and/or supplements was inversely correlated with serum vitamin B12 levels, which could be interpreted as an inductive effect of vitamin B12 deficiency. Recent studies in the US with the elderly population exposed to FA fortification observed that the combination of low vitamin B12 levels $(<148 \mathrm{pmol} / \mathrm{L}$ or MMA > $210 \mathrm{nmol} / \mathrm{L}$ ) and high folate levels $(>59 \mathrm{nmol} / \mathrm{L}$ ) increased the risk of cognitive impairment by 5 times (7).

Corroborating these findings, Morris et al. (8) evaluated the impact of non-metabolized FA (as a biomarker) on the cognitive function of elderly in the 
NHANES in the post-fortification period and found that the simple presence of circulating non-metabolized FA was related with poorer cognitive performance in elderly people with vitamin B12 deficiency. In the present study, despite greater FA consumption among older people with a low MMSE score, the difference was no longer statistically significant after adjustment for energy intake (per $1000 \mathrm{kcal}$ ). FA intake from both fortification and supplements was $239.10 \mu$ /day, similar to the $280 \mu$ /day reported by Morris et al. (8), which was associated with the presence of the non-metabolized form in the blood.

Conflicting results exist for countries that have opted for voluntary fortification; there was no effect among the British elderly (31), while there was a nearly 3.5time greater risk of cognitive decline, as assessed by the MMSE, in elderly Australians (29). Conversely, re-enforcing the benefits of food-based, non-synthetic folate, Doets et al. (32) observed a positive association between plasma folate levels and cognitive performance among elderly Norwegians not exposed to fortification. This was probably due to the low prevalence of vitamin B12 deficiency and supraphysiological folate levels, attributed to the low use of supplements by the population.

Studies also suggest that excess FA can induce functional vitamin B12 deficiency, as evidenced by increases in Hcy, MMA, and holo-TC $(7,9,12)$ that are associated with cognitive impairment among elderly Americans (7). Despite an increase in biomarkers, no relation with MMSE was observed in a cohort of elderly Latinos, potentially owing to the small subgroup of individuals with both high serum folate levels and vitamin B12 deficiency (33). In the present study, the sample size also compromised our ability to detect significant relationships. However, if we disregard the MMA levels, given that almost one third of the patients was at risk of functional B12 deficiency $(<400 \mathrm{pmol} / \mathrm{L})$, it is possible that excess FA may have contributed to the high frequency $(65 \%)$ of hyperhomocysteinemia.

The reported influence of Hcy level on cognitive function was not observed in the present study. High Hcy levels, at levels that affect memory function, are associated with low folate status, a finding that has become uncommon in post-fortification studies. Furthermore, a relationship with a decrease in MMSE has been more common in longitudinal studies among individuals with lower scores and of older age (27).

The significant elevation in serum folate in the Brazilian population after fortification (30) could also explain the absence of macrocytosis in the present study sample, considering that no change was observed in mean corpuscular volume. Similar results were observed in other countries that adhered to fortification $(8,13,34)$ and also among elderly Brazilians, in whom macrocytosis and folate deficiency were not detected despite vitamin B12 deficiency in 11\%, evaluated using MMA (35). This supports the hypothesis that FA fortification may mask the hematological signs of vitamin B12 deficiency (12).
Based on this evidence, the Institute of Medicine recommends that American adults aged $\geq 50$ years follow the dosage recommendations for synthetic replacement of vitamin B12 (19). There is still speculation as to whether the joint fortification of vitamin B12 and FA minimizes the risk of cognitive impairment in the elderly population. Despite measures that are, in theory, capable of minimizing the problem, chronic exposure to non-metabolized FA is still concerning, without an understanding of its potential long-term damage to the body $(6,14)$.

Given the limitations of the present study, such as its cross-sectional design, sample size, female predominance, and absence of specific functional markers for vitamin B12, it was not possible to reproduce the same relationships as those identified in American population studies. Despite the limitations, the results support the risks of FA intake on B12 status in the elderly that are suggested in the literature. The MMSE is commonly used as a global assessment method of cognitive function, and the use of the Brazilian version, adjusted for education level, was considered more appropriate for the present sample. One strength in the evaluation of FA consumption was the use of four 24-hour dietary recalls and the adjustment for FA quantities established for fortification in Brazil, in addition to the evaluation of serum folate levels.

In conclusion, there were no significant relationships between the investigated biochemical variables (B12, folate, Hcy, and iron) and the MMSE results. However, despite the observation of serum vitamin B12 deficiency in only $5 \%$ of the sample, using the $<400 \mathrm{pmol} / \mathrm{L}$ cutoff point, the levels for $27.5 \%$ of the elderly were in the range for a risk of functional deficiency; these participants tended to have poorer MMSE scores and to be older. FA consumption had a negative influence on serum vitamin B12 levels and explained the presence of supraphysiological levels $(7.5 \%)$ and absence of classic folate deficiency and macrocytosis.

Collectively, these findings reinforce present data that indicate that FA may directly or indirectly worsen the mental health of the elderly and the importance of maintaining good B12-related nutritional status among the elderly receiving FA fortification or supplementation. Given the seriousness of the evidence, a thorough investigation is required with representative samples of the elderly population that includes functional biomarkers such as MMA and holo-TC, as well as nonmetabolized FA and gene polymorphisms related with folate metabolism.

Acknowledgments: We express our gratitude to Silvana Cardoso and Roberto Ferraboli for their help collecting and analyzing the blood samples. We would like to thank Karen Barbosa Müller for their comments and suggestions in the preparation of this article. We also thank the team of Projeto Senior para a Vida Ativa and gerontology and psychology clinic of São Judas Tadeu University for their help conducting the neuropsychological tests.

Funding: The present study was funded by the São Judas Tadeu University. All authors declare that they have no conflicts of interest. No competing financial 
interests exist.

Ethical Standards: This research complies with the current laws of the country in which they were performed".

\section{References}

1. Instituto Brasileiro de Geografia e Estatística- IBGE. Indicadores sociodemográficos e de Saúde no Brasil. 2009. IBGE, Rio de Janeiro.

2. Malafaia G. The consequences of nutritional deficits associated to immunosenescence in the health of elderly. Arq Bras Ciênc Saúde 2008;33:168-176.

3. Varela-Moreiras G, Murphy MM, Scott JM. Cobalamin, folic acid, and homocysteine. Nutr Rev 2009;67:S69-S72.

4. Andrès E, Vogel T, Federici L, Zimmer J, Ciobanu E, Kaltenbach G. Cobalamin deficiency in elderly patients: a personal view. Curr Gerontol Geriatr Res 2008;848267.

5. Werder SF. Cobalamin deficiency, hyperhomocysteinemia, and dementia. Neuropsychiatr Dis Treat 2010;6:159-195.

6. Cuskelly GJ, Mooney KM, Young IS. Folate and vitamin B12: friendly or enemy nutrients for the elderly. Proc Nutr Soc 2007;66:548-558.

7. Selhub J, Morris MS, Jacques PF, Rosenberg IH. Folate-vitamin B-12 interaction in relation to cognitive impairment, anemia, and biochemical indicators of vitamin B-12 deficiency. Am J Clin Nutr 2009;89:702S-706S.

8. Morris MS, Jacques PF, Rosenberg IH, Selhub J. Circulating unmetabolized folic acid and 5-methyltetrahydrofolate in relation to anemia, macrocytosis, and cognitive test performance in American seniors. 2010;91:1733-1744.

9. Selhub J, Morris MS, Jacques PF. In vitamin B12 deficiency, higher serum folate is associated with increased total homocysteine and methylmalonic acid concentrations. Proc Natl Acad Sci USA 2007;104:19995-20000.

10. Christensen KE, Mikael LG, Leung KY, et al. High folic acid consumption leads to pseudo-MTHFR deficiency, altered lipid metabolism, and liver injury in mice. Am J Clin Nutr 2015;101:646-658.

11. Mitchell ES, Conus N, Kaput J. B vitamin polymorphisms and behavior: evidence of associations with neurodevelopment, depression, schizophrenia, bipolar disorder and cognitive decline. Neurosci Biobehav Rev 2014;47:307320.

12. Smith AD, Refsum H. Do we need to reconsider the desirable blood level of vitamin B12? J Intern Med 2012;271:179-182.

13. Wyckoff KF, Ganji V. Proportion of individuals with low serum vitamin B-12 concentrations without macrocytosis is higher in the post folic acid fortification period than in the pre folic acid fortification period. Am J Clin Nutr 2007;86:1187-1192.

14. Lucock M, Yates Z. Folic acid fortification: a double-edged sword. Curr Opin Clin Nutr. Metab Care 2009;12:555-564.

15. Brasil. Ministério da Saúde. RDC n. 344, de 13 de dezembro de 2002. Aprova o regulamento técnico para a fortificação das farinhas de trigo e das farinhas de milho com ferro e ácido fólico. http: / / www.anvisa.gov.br/ Legis/resol/2002/344_02rdc.htm. Accessed July 2011

16. Organização Pan-Americana. XXXVI Reunión del Comitê Asesor de Investigaciones en Salud - Encuestra Multicêntrica - Salud Beinestar y Envejecimiento (SABE) en América Latina e el Caribe-Informe preliminar. 2002. http:/ / www.opas.org/program/sabe.htm. Accessed 25 April 2012

17. World Health Organization. Obesity: preventing and managing the global epidemic: report of a WHO Consultation on Obesity, Geneva, 3-5 June 1997 (WHO/NUT/NCD 98.1). 1997. World Health Organization, Geneva

18. Bottero A, Lauritano D, Spadari F, Zambellini Artini M, Salvato A Atrophy of the oro-pharyngeal mucosa caused by vitamin B12 and folic acid deficiency.
Etiopathologic aspects and clinico-therapeutic problems. Minerva Stomatol 1997; 46:359-374.

19. Institute of Medicine. Dietary Reference Intakes for Thiamin, Riboflavin, Niacin, Vitamin B6, Folate, Vitamin B12, Pantothenic Acid, Biotin, and Choline. The National Academies Press. 1998. http://www.nap.edu/ catalog/6015.html. Accessed 25 April 2011

20. Tabela Brasileira de Composição de Alimentos (TACO). $4^{\mathrm{a}}$, ed. rev. e amp. Campinas: NEPA-UNICAMP; 2011. [Version xls]. 2012. www.unicamp.br/ nepa/taco/tabela.php. Accessed 4 July 2012

21. US Department of Agriculture, Agriculture Research Service. USDA National Nutrient Database for Standard Reference, Release 25 online. 2012. http:/ / www.ars.usda.gov/ba/bhnrc/ndl. Accessed Jul/Nov 2012

22. Lindenbaum J, Savage DG, Stabler SP, Allen RH. Diagnosis of cobalamin deficiency: II. Relative sensitivities of serum cobalamin, methylmalonic acid, and total homocysteine concentrations. Am J Hematol 1990;34:99-107.

23. Vogiatzoglou A, Smith AD, Nurk E, et al. Dietary sources of vitamin B-12 and their association with plasma vitamin B-12 concentrations in the general population: the Hordaland Homocysteine Study. Am J Clin Nutr 2009;89:1078-1087.

24. World Health Organization. Nutritional anaemias. Report of a WHO scientific group (Technical Report Series, No. 405). World Health Organization, Geneva. 1968. http://whqlibdoc.who.int/trs/WHO_TRS_405. pdf. Accessed 13 September 2012

25. Refsum $\mathrm{H}$, Smith AD, Ueland PM, et al. Facts and recommendations about total homocysteine determinations: an expert opinion. Clin Chem 2004;50:332.

26. Brucki SM, Nitrini R, Caramelli P, Bertolucci PH, Okamoto IH. Suggestions for utilization of the Min-Mental State Examination in Brazil. Ar NeuroPsiquiatr 2003;61:777-781.

27. Morris MS. The role of $\mathrm{B}$ vitamins in preventing and treating cognitive impairment and decline. Adv Nutr 2012;3:801-812.

28. Morris MS, Selhub J, Jacques PF. Vitamin B-12 and folate status in relation to decline in scores on the Mini-Mental State Examination in the Framingham Heart Study. J Am Geriatr Soc 2012;60:1457-1464.

29. Moore EM, Ames D, Mander AG, et al. Among vitamin B12 deficient older people, high folate levels are associated with worse cognitive function: combined data from three cohorts. J Alzheimers Dis 2014;39:661-668.

30. Britto JC, Cançado R, Guerra-Shinohara EM. Concentrations of blood folate in Brazilian studies prior to and after fortification of wheat and cornmeal (maize flour) with folic acid: a review. Rev Bras Hematol Hemoter 2014;36:275-286.

31. Clarke $\mathrm{R}$, Sherliker $\mathrm{P}$, Hin $\mathrm{H}$, et al. Folate and vitamin B12 status in relation to cognitive impairment and anaemia in the setting of voluntary fortification in the UK. Br J Nutr 2008;100:1054-1059.

32. Doets EL, Ueland PM, Tell GS, et al. Interactions between plasma concentrations of folate and markers of vitamin $\mathrm{B}(12)$ status with cognitive performance in elderly people not exposed to folic acid fortification: the Hordaland Health Study. Br J Nutr 2014;111:1085-1095.

33. Miller JW, Garrod MG, Allen LH, Haan MN, Green R. Metabolic evidence of vitamin B-12 deficiency, including high homocysteine and methylmalonic acid and low holotranscobalamin, is more pronounced in older adults with elevated plasma folate. Am J Clin Nutr 2009;90:1586-1592.

34. Hirsch S, de la Maza P, Barrera G, Gattás V, Petermann M, Bunout D. The Chilean flour folic acid fortification program reduces serum homocysteine levels and masks vitamin B-12 deficiency in elderly people. J Nutr 2002;132:289-291.

35. Xavier JM, Costa FF, Annichino-Bizzacchi JM, Saad ST. High frequency of vitamin B12 deficiency in a Brazilian population. Public Health Nutr 2010;13:1191-1197. 